This is an open access article under the CC BY-NC-ND license (https://creativecommons.org/licenses/by-nc-nd/3.0/) Issue III, November 2020

ISSN 2707-9481

ISBN 978-601-323-207-2

https://doi.org/10.31643/2020.039

\author{
Svetlana Rudneva \\ Russian University of transport, Russia \\ Email: se_rudneva@mail.ru \\ ORCID ID https://orcid.org/0000-0003-3187-0351
}

\title{
Medical and sanitary issues on the Railways of Russia in 1917
}

\begin{abstract}
The article is devoted to the issue of providing medical care to railway workers after the February revolution of 1917 in Russia. Social transformations of the revolutionary period also affected railway transport, affecting, among other things, the medical and sanitary issue. The purpose of the study was to study the changes that took place in the structure of medical and sanitary Affairs in railway transport in 1917. Since it existed before the February revolution of 1917 railway medicine could not satisfy the railway workers, and they considered the situation of medicine on the Railways abnormal. Railway workers clearly recognized the need for a radical reorganization of the formulation of railway medicine. They expressed their wishes that this issue should receive comprehensive coverage at the all-Russian Railway Congress, and that not only doctors, but also middle and Junior medical personnel of other categories (paramedics, midwives, pharmacists, disinfectants, etc.) should be invited to participate in the railway medicine section, as people who are closer and more familiar with the needs of railway workers. As a result of the research, the article shows that the all-Russian constituent railway Congress, held from July 15 to August 25, 1917, in Moscow, contributed to the formulation and progress of scientific and sanitary Affairs that served the interests of railway workers, taking into account the specifics of the revolutionary period.
\end{abstract}

Keywords: medical and sanitary issues, Railways, revolution of 1917.

Cite this article as: Rudneva S. (2020). Vrachebno-sanitarnyy vopros na zheleznykh dorogakh Rossii v 1917 godu [Medical and sanitary issues on the Railways of Russia in 1917]. Challenges of Science. Issue III, p.: 240-245. (In Russian). https://doi.org/10.31643/2020.039

\author{
Светлана Руднева \\ Российский университет транспорта, Россия \\ Email: se_rudneva@mail.ru \\ ORCID ID https://orcid.org/0000-0003-3187-0351
}

\section{Врачебно-санитарный вопрос на железных дорогах России в 1917 году}

\begin{abstract}
Абстракт. Статья посвящена рассмотрению вопроса постановки медицинской помощи железнодорожникам после Февральской революции 1917 г. в России. Общественные трансформации революционного периода затронули и железнодорожный транспорт, сказавшись, в том числе, и на врачебносанитарном вопросе. Цель исследования состояла в изучении происходивших перемен в постановке врачебносанитарного дела на железнодорожном транспорте в 1917 году. Поскольку существовавшая до Февральской революции 1917 г. железнодорожная медицина не могла удовлетворить железнодорожников, положение медицины на железных дорогах они считали ненормальным. Железнодорожниками ясно сознавалась необходимость коренной реорганизации постановки железнодорожной медицины. Высказывались пожелания,
\end{abstract}


чтобы этот вопрос получил всестороннее освещение на Всероссийском железнодорожном съезде, чтобы к участию в секции железнодорожной медицины были приглашены не одни только врачи, а также средний и младший медицинский персонал других категорий (фельдшера, акушерки, фармацевты, дезинфекторы и т.п.), как лиц ближе стоящих и в большей степени знакомых с нуждами железнодорожников. В результате проведенного исследования в статье показано, что Всероссийский учредительный железнодорожный съезд, проходивший с 15 июля по 25 августа 1917 г. в Москве, внес свой вклад постановку и ход научно-санитарного дела, обслуживавшего интересы железнодорожников, с учетом специфики революционного периода.

Ключевые слова: врачебно-санитарный вопрос, железные дороги, революция 1917 года.

\section{Введение}

После Февральской революции 1917 г. в России, крушения монархии, прихода к власти 2 марта 1917 г. Временного правительства, в период продолжавшейся Первой мировой войны 1914-1918 гг., наряду с другими многочисленными проблемами, обозначился врачебно-санитарный вопрос на железных дорогах страны. Постановка медицинской помощи железнодорожным служащим и членам их семейств вызывала нарекания со стороны железнодорожников. Реформаторы постфевральского периода считали, что железнодорожной медицине старым режимом были присвоены несвойственные ей функции. В частности, медицинскому персоналу администрация вменила в обязанность проверять не явившихся на службу, «т.е. медицинский персонал должен был заниматься сыском» [1]. Также недовольство железнодорожников вызывала другая функция медицинского персонала, заключавшаяся в защите интересов казны, т.е. предпринимателя. На железнодорожную службу должен был приниматься безусловно здоровый сотрудник, чтобы потеря его трудоспособности наступила в возможно более отдаленном будущем. Лечение железнодорожного населения нередко заключалось только в регистрации больных. Не имелось достаточного количества железнодорожных больниц. Медицинскому персоналу с большим трудом удавалось помещать железнодорожников в городские, земские, частные больницы, поскольку число нуждающихся в больничном лечении всегда превышало количество коек в больницах. Лечение железнодорожников на дому ввиду отдаленности квартир от железнодорожных станций и отсутствия достаточного количества медицинского персонала было проблематичным. Врачи были перегружены возложенными на них обязанностями, собственно для лечения у них оставалось мало времени. Непосредственно врачебные обязанности весьма часто возлагались на фельдшеров, что для них являлось непосильным и страдали интересы лечебного дела.

Практиковавшееся пользование медикаментами из железнодорожных аптек также подвергалось критике. Существовавший нормальный каталог медикаментов, которым должен был руководствоваться медицинский персонал, не включал необходимых средств, уже признанных практической медициной, поэтому пользование железнодорожников медикаментами производилось в некоторых случаях за их счет.

На больших железнодорожных пунктах специальные врачи если и существовали, то не по всем специальностям, консультации их носили случайный характер. Зубоврачебная помощь на железных дорогах почти совершенно отсутствовала, за неимением оборудованных зубоврачебных кабинетов. В санитарно-гигиеническом отношении с казенными квартирами дело обстояло не лучше. Тип квартиркомнат или общих казарм для рабочих, а также контор, мастерских депо, дежурных комнат, не удовлетворял основным требованиям гигиены, поскольку санитарный надзор медицинского персонала за казенными помещениями не осуществлялся.

Существовавшая до Февральской революции 1917 г. железнодорожная медицина не могла удовлетворить железнодорожников, положение медицины на железных дорогах они считали ненормальным. Железнодорожниками ясно сознавалась необходимость коренной реорганизации 
постановки железнодорожной медицины. Высказывались пожелания, чтобы этот вопрос получил всестороннее освещение на всероссийском железнодорожном съезде, чтобы к участию в секции железнодорожной медицины были приглашены не одни только врачи, а также средний и младший медицинский персонал других категорий (фельдшера, акушерки, фармацевты, дезинфекторы и т.п.), как лиц ближе стоящих и в большей степени знакомых с нуждами железнодорожников [2].

После Февральской революции 1917 г. в деле организации железнодорожной медицины наметились перемены. В мае 1917 г. в особом совещании по домостроительству при министерстве путей сообщения рассматривался вопрос об организации для железнодорожных служащих санаториев, климатических станций, грязелечебниц, кумысолечебниц и тому подобных лечебных заведений. Всех постоянных служащих и рабочих в мастерских на железных дорогах насчитывалось около 1 миллиона человек. Лечебных мест на железных дорогах было совершенно недостаточно, между тем в летние месяцы единовременно пользовались отпуском до 9.000 человек.

Организация лечебных заведений для железнодорожных служащих особым совещанием признавалась необходимой, было постановлено для этой цеди приобрести соответствующие участки земли в районах Закавказских, Владикавказской, Черноморской, Крымской, Московско-Курской и Самарско-Златоустинской железных дорог. На создание лечебных заведений и дач-общежитий для отдыха требовалось свыше 30 миллионов рублей [3].

Учитывая фактор продолжавшейся войны, в которой непосредственное участие принимали железнодорожники, для постановки врачебно-санитарного вопроса на железных дорогах чрезвычайно важное значение имело оживление деятельности врачебно-санитарных организаций страны в целом, в том числе состоявшийся в мае 1917 г. Съезд делегатов врачебно-санитарных организаций. На открытии съезда представителей, объединенных губернских, областных и фронтовых врачебно-санитарных организаций, созванного советом при комиссаре Временного правительства по управлению верховного начальника санитарной и эвакуационной части, присутствовал министр государственного призрения князь Д.И. Шаховской, приветствовавший членов съезда. Он подчеркнул необходимость неразрывного контакта министерства с представителями общественной медицины и единения с представителями науки и земских организаций. Министерство не претендовало на присвоение себе руководящих функций в вопросах, предстоящих обсуждению на съезде.

Д.И. Шаховской указал на необходимость подготовки кадров деятелей по общественному призрению на местах и подробно остановился на задачах министерства в связи с войной, заключавшихся в призрении увечных и в возвращении их к труду, и в призрении сирот. В области призрения увечных невозможно было предпринять ни единого шага без представителей общественной медицины. Министр выразил уверенность, что съезд даст в этом отношении важные рекомендации, а также будет способствовать организации тесного общения между министерством, местными общественными организациями, врачами и представителями науки.

Комиссар Временного правительства член Государственной Думы В.И. Алмазов доложил проект «Положения о центральном врачебно-санитарном совете при Временном правительстве». Этот Совет учреждался вместо упраздняемого управления верховного начальника санитарной и эвакуационной части. В прениях по докладу приняли участие несколько делегатов, из которых многие указывали на ряд дефектов проекта, как, например, невключение в состав учреждаемого совета представителей фабрично-заводской медицины и т.п. [4].

На съезде были заслушаны доклады 3.Г. Френкеля «Об организации областных санитарнотехнических бюро», доктора Я. Ю. Каца «Об участии врачебно-санитарных органов в деле помощи увечным», доктора В.А. Воробьева «Об общем плане организации санитарно-курортного лечения для больных и увечных воинов», профессора О. В. Петерсона «О положении призрения прокаженных на переживаемое время», профессора Н. Н. Бурденко «Об изменениях во врачебно-санитарной организации военного ведомства и ближайших задачах, стоящих перед ведомством в связи с переживаемым временем». Кроме того, на съезде был прочитан доклад «Об организации местных губернских, уездных, городских и областных объединенных врачебно-санитарных органов». 
По докладу комиссара Временного правительства В. И. Алмазова о Центральном военносанитарном совете при Временном правительстве съезд принял ряд резолюций, в которых указывалось, что тяжелые условия врачебно-санитарного дела в стране ставили неотложно срочный вопрос об издании Временным правительством положения о названном совете. Главной задачей совета была определена разработка проекта положения о постоянных центральных и местных врачебно-санитарных органах.

По докладу о мобилизации врачей мужчин и женщин для удовлетворения наличных острых нужд фронта, съезд считал, что настоящая мобилизация, захватывая последние кадры ответственных тыловых работников, должна быть осуществлена особо продуманно и осторожно. Ввиду этого мобилизация должна была осуществляться только по получении срочных заключений местных губернских городских санитарных советов о списках призываемых. Этим советам следовало предоставить право указания врачей, неподлежащих призыву, как незаменимых, призыв которых угрожал бы целостности и жизненности тыловых врачебно-санитарных организаций. Окончательное заключение по вопросу о списках призываемых врачей должно было принадлежать особой комиссии из врачей и представителей центрального врачебно-санитарного совета при главном военносанитарном управлении.

Комиссией по рассмотрению вопроса о принципах мобилизации ратников ополчения и женщин врачей был составлен список врачей, которые совершенно не подлежали призыву. В него входили разных категорий земские врачи, городские врачи, служащие на железных дорогах и водных путях, в горнопромышленных предприятиях, ординарные и экстраординарные профессора университетов и медицинских курсов, приват-доценты, читавшие обязательные курсы, главный врачебный инспектор министерства внутренних дел, заведующие бактериологическими институтами, изготовлявшими сыворотки и т.п. По принятии резолюций съездом был выслушан ряд речей об итогах работ съезда и была выражена благодарность комиссару Временного правительства члену Государственной Думы В.И. Алмазову и его ближайшему сотруднику доктору 3.Г. Френкелю, после чего съезд был объявлен закрытым [5].

Комиссия по освобождению от призыва врачей при главном военно-санитарном управлении уведомила правительственные и частные высшие медицинские учреждения, что по вопросу об оставлении на местах «ныне призываемых врачей преподавателей таких учреждений», она постановила решение этого вопроса предоставить местному коллегиальному ученому совету каждого учреждения, с тем, чтобы списки врачей, подлежавших оставлению на местах, были препровождены в ближайшее время в главное военно-санитарное управление для утверждения этих комиссий [6].

Как и планировалось, врачебно-санитарный вопрос на железных дорогах рассматривался на открывшемся 15 июля 1917 г. в Москве Всероссийском учредительном железнодорожном съезде. 25 июля на 11-м заседании съезда делегат Климкин сделал краткий доклад о частном заседании экономического совета, с участием делегатов железнодорожного съезда. В этом заседании обсуждались вопросы об улучшении дела транспорта, врачебно-санитарного вопроса [7]. На Всероссийском учредительном железнодорожном съезде была также создана врачебно-санитарная комиссия съезда. На съезде с докладом о государственном страховании выступил делегат А.Ф. Бровцын. В докладе отмечалось, что страхование на случай болезни вполне может быть заменено обязательством, возложенном на железные дороги, оказывать за счет дорог бесплатную медицинскую помощь с выдачей лекарств и предоставлением всех видов лечения. Высказывалось пожелание удлинить существовавший срок обязательства лечить служащих. Предлагалось возложить на будущий исполнительный комитет Всероссийского съезда социал-демократов служащих заботу о проведении в жизнь реорганизации врачебной службы на железной дороге, «положив в основание разработки широкий доступ союзных организаций служащих и рабочих» к постановке и управлению делами врачебного дела на железных дорогах или о передаче в союз определенных от дороги средств для самостоятельного ведения врачебного дела союзом [8].

Всероссийский учредительный железнодорожный съезд продолжался с 15 июля по 25 августа, т.е. 42 дня. Высказывались надежды, что все постановления съезда, в пределах компетенции союза, а 
равно и пожелания в других областях государственной и железнодорожной жизни будут способствовать поднятию дела транспорта, улучшения железнодорожного хозяйства и борьбе с разрухой в стране [9]. В особенности плодотворными и обстоятельными, всесторонне охватывающими вопросы, явились труды некоторых комиссий съезда, например, трудовой и пенсионно-страховой. Четыре отрасли железнодорожного хозяйства: продовольственная, культурнопросветительная, врачебно-санитарная и пенсионно-страховая, согласно телеграмме Г.С. Тохтамышева, всецело отходили в ведение союза, и в этих областях союзу открывалось широкое поле творческой, созидательной работы. Высказывалось намерение на заложенном съезде фундаменте «продолжать постройку здания свободного труда и культуры» [10], в том числе и во врачебно-санитарном деле на железных дорогах страны.

\section{Выводы}

Врачебно-санитарная, пенсионно-страховая отрасли железнодорожного хозяйства передавались в заведывание служащих лиц их организаций. Условия и способы передачи должен был определить исполнительный комитет Всероссийского железнодорожного союза по соглашению с министерством путей сообщения. Главные дорожные комитеты должны были готовиться, чтобы с честью выполнить возлагаемые на них трудные задачи. Нужно было разработать планы управления и создать специальные органы для заведывания ими. Главным комитетам не рекомендовалось самим непосредственно браться за управление этими отраслями. Такое управление не привело бы к успеху, поскольку «всякое управление из центра, будь то управление одного лица или целой коллегии, есть управление бюрократическое», а также потому, что в составе комитетов нет для этого достаточного количества сведущих людей. Для правильной постановки этих отраслей на дорогах признавалось необходимым управление ими организовать на автономных началах, при участии и под контролем органов Всероссийского железнодорожного союза. Во главе отрасли должен был находиться особый комитет, в который, прежде всего, необходимо было привлечь специалистов, обслуживающих эту отрасль, затем представителей других отраслей, общественных организаций и соответствующего министерства. В комитет для заведывания врачебно-санитарным делом кроме членов данного комитата следовало привлечь представителей высшего и низшего врачебных персоналов, фармацевтов, других, кроме союза, общественных организаций на дороге, министерства труда и т.д. Отмечалось, что подробности организации для врачебно-санитарного дела легко выработать, воспользовавшись трудами всероссийских съездов врачей и железнодорожного съезда при участии представителей от союзов врачей. Таким образом, построенный комитет даст гарантию правильной и прочной постановки дела. Специалисты лучше кого бы то ни было увидят и смогут исправить недостатки дела, а представители других отраслей железнодорожного хозяйства и министерства будут наблюдать, чтобы при исправлении этих недостатков не пострадали другие отрасли, а также интересы государства. Относительно прочности организации, подчеркивалось, что состав существовавших главных комитетов непрерывно менялся и могло случиться, что главный комитет, успешно наладивший дело, мог быть заменен новым составом, не способным к ведению дела. Тогда охрана труда железнодорожников, потерявшим в течение многих лет службы здоровье, подверглась бы серьезной опасности. Эта опасность устранялась, если во главе отрасли стоял бы особый, до известной степени независимый комитет, составленный по вышеуказанному плану [11].

Устав Всероссийского железнодорожного союза, принятый Всероссийским железнодорожным учредительным съездом, отмечал, что это организация, объединявшая всех железнодорожников Российских железных дорог для решения государственных задач, посредством управления, в том числе, отраслями, обслуживающими непосредственно интересы железнодорожников, в том числе врачебно-санитарные. В обязанности главного дорожного комитета входило объединение деятельности всех управлений теми отраслями железнодорожных предприятий, которые обслуживают интересы собственно железнодорожников, и врачебно-санитарный, в частности [1]. Центральный исполнительный комитет Всероссийского железнодорожного союза объединял, таким 
образом, всю постановку и ход научно-санитарного дела, обслуживавшего интересы железнодорожников.

Ссылка на данную статью: Руднева С. (2020) Врачебно-санитарный вопрос на железных дорогах России в 1917 году. Материалы Международной практической интернет-конференции «Актуальные проблемы науки» [Challenges of Science]. Выпуск III, стр. 240-245. https://doi.org/10.31643/2020.039

\section{Литературы}

[1] Railway worker's voice. 1917. June 21. (Голос железнодорожника. 1917. 21 июня).

[2] Ibid. (Там же).

[3] Bulletin of ways of communication. 1917. №. 19. Рp. 91-92. (Вестник путей сообщения. 1917. №19. С. 91-92).

[4] Speech. 1917. Мау 24. (Речь. 1917. 24 мая).

[5] Speech. 1917. Мау 25. (Речь. 1917. 25 мая).

[6] Speech. 1917. July 22. (Речь. 1917. 22 июля).

[7] The voice of a railway worker. 1917. №21. (Голос железнодорожника. 1917. №21).

[8] The voice of a railway worker. 1917. №21. (Голос железнодорожника. 1917. №27).

[9] История становления и развития медико-санитарной службы на железнодорожном транспорте России. Агавелян Н.Г., Аджигитова Е.В., Артамонова О.А., Артемьева Н.Н., Артёменков Ю.М., Атьков О.Ю., Афанасьева Г.Г., Базазьян А.Г., Вильк М.Ф., Грачёва Р.П., Демидова В.В., Долотин С.В., Дубровская Т.А., Елизаров Б.Б., Зайцев А.Н., Зубова Л.В., Калинина И.А., Каськов Ю., Кон С.В., Кондакова К.И. и др. Москва, 2016.

[10] The voice of a railway worker. 1917. №. 29. September 1. (Голос железнодорожника. 1917. №29. 1 сентября).

[11] The voice of a railway worker. 1917. №. 30. September 7. (Голос железнодорожника. 1917. №30. 7 сентября).

[12] The voice of a railway worker. 1917. №. 31. September 19. (Голос железнодорожника.1917. №31. 19 сентября).

\section{References}

[1] Railway worker's voice. 1917. June 21. (Voice of the railwayman. 1917. June 21). (In Russian).

[2] Ibid. (Ibid.). (In Russian).

[3] Bulletin of ways of communication. 1917. No. 19. Pp. 91-92. (Bulletin of the ways of communication. 1917. No. 19. S. 9192). (In Russian).

[4] Speech. 1917. May 24. (Speech. 1917. May 24). (In Russian).

[5] Speech. 1917. May 25. (Speech. 1917. May 25). (In Russian).

[6] Speech. 1917. July 22. (Speech. 1917. July 22). (In Russian).

[7] The voice of a railway worker. 1917. No. 21. (Voice of the railroad worker. 1917. №21). (In Russian).

[8] The voice of a railway worker. 1917. No. 21. (The voice of the railroad worker. 1917. No. 27). (In Russian).

[9] Istoriya stanovleniya i razvitiya mediko-sanitarnoy sluzhby na zheleznodorozhnom transporte Rossii [History of formation and development of medical and sanitary service on railway transport in Russia]. Agavelyan N. G., Adzhigitova E. V., Artamonova O. A., Artemyeva N. N., Artemenkov Yu. M., Atkov O. Yu., Afanasyeva GG, Bazazyan AG, Vilk MF, Gracheva RP, Demidova VV, Dolotin SV, Dubrovskaya TA, Yelizarov BB, Zaitsev AN, Zubova LV, Kalinina IA, Kaskov Yu., Kon SV, Kondakova KI, etc. Moscow, 2016. (In Russian).

[10] The voice of a railway worker. 1917. No. 29. September 1. (Voice of the railwayman. 1917. No. 29. September 1). (In Russian).

[11] The voice of a railway worker. 1917. No. 30 September 7. (The voice of the railwayman. 1917. No. 30. September 7). (In Russian).

[12] The voice of a railway worker. 1917. No. 31. September 19. (Voice of the railway worker. 1917. No. 31. September 19). (In Russian). 